\title{
Lectin-deficient Calreticulin Retains Full Functionality as a Chaperone for Class I Histocompatibility Molecules
}

\author{
Breanna S. Ireland, ${ }^{*+}$ Ulf Brockmeier, ${ }^{*+}$ Christopher M. Howe, ${ }^{\ddagger}$ Tim Elliott, ${ }^{\ddagger}$ \\ and David B. Williams*
}

\author{
*Departments of Biochemistry and Immunology, University of Toronto, Toronto, Ontario M5S 1A8, Canada; \\ and $¥$ Cancer Sciences Division and CRC Medical Oncology Unit, University of Southampton School of \\ Medicine, Southampton SO16 6YD, United Kingdom
}

Submitted October 19, 2007; Revised February 19, 2008; Accepted March 5, 2008

Monitoring Editor: Benjamin Glick

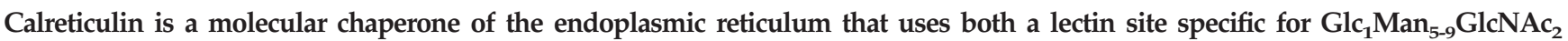
oligosaccharides and a polypeptide binding site to interact with nascent glycoproteins. The latter mode of substrate recognition is controversial. To examine the relevance of polypeptide binding to protein folding in living cells, we prepared lectin-deficient mutants of calreticulin and examined their abilities to support the assembly and quality control of mouse class I histocompatibility molecules. In cells lacking calreticulin, class I molecules exhibit inefficient loading of peptide ligands, reduced cell surface expression and aberrantly rapid export from the endoplasmic reticulum. Remarkably, expression of calreticulin mutants that are completely devoid of lectin function fully complemented all of the class I biosynthetic defects. We conclude that calreticulin can use nonlectin-based modes of substrate interaction to effect its chaperone and quality control functions on class I molecules in living cells. Furthermore, pulse-chase coimmunoisolation experiments revealed that lectin-deficient calreticulin bound to a similar spectrum of client proteins as wild-type calreticulin and dissociated with similar kinetics, suggesting that lectin-independent interactions are commonplace in cells and that they seem to be regulated during client protein maturation.
\end{abstract}

\section{INTRODUCTION}

Within the endoplasmic reticulum (ER), the calnexin (Cnx)/ calreticulin (Crt) chaperone system plays an important role in the folding and quality control of Asn-linked glycoproteins (Helenius and Aebi, 2004; Williams, 2006). Studies with a variety of glycoprotein substrates have demonstrated that these chaperones can promote folding by minimizing aggregation and by recruitment of the ERp57 thiol oxidoreductase. They also retard the export of nonnative glycoprotein conformers from the ER and deliver misfolded glycoproteins to the ER-associated degradation system.

The mechanisms whereby $\mathrm{Cnx}$ and Crt recognize nonnative glycoproteins and effect their functions remain controversial. Both chaperones are lectins that recognize the monoglucosylated processing intermediates $\mathrm{Glc}_{1} \mathrm{Man}_{5-9} \mathrm{GlcNAc}_{2}$ (Ware et al., 1995; Spiro et al., 1996), and it has been proposed that the availability of the terminal glucose on these oligosaccharides regulates cycles of chaperone binding and release (Hebert et al., 1995). Cycles are driven by the opposing

This article was published online ahead of print in $M B C$ in Press (http://www.molbiolcell.org/cgi/doi/10.1091/mbc.E07-10-1055) on March 12, 2008.

+ These authors contributed equally to this work.

Address correspondence to: Dr. David B. Williams (david.williams@ utoronto.ca).

Abbreviations used: $\beta_{2} \mathrm{~m}, \beta_{2}$-microglobulin; Cnx, calnexin; Crt, calreticulin; ER, endoplasmic reticulum; MHC, major histocompatibility complex; PLC, peptide loading complex; TAP, transporter associated with antigen processing; UGGT, UDP-glucose:glycoprotein glucosyltransferase. actions of glucosidase II that removes the glucose and UDPglucose:glycoprotein glucosyltransferase (UGGT) that reattaches it. Glycoprotein conformational state is detected by UGGT, which only adds glucose to nonnative glycoprotein conformers (Caramelo et al., 2003). Prolonged residence of a nonnative glycoprotein within this cycle would retard its export from the ER, and proper folding may be promoted by the thiol oxidoreductase ERp57, which associates with both Cnx and Crt (Frickel et al., 2002; Leach et al., 2002). It is unclear how substrate aggregation is inhibited in this model, although it is thought that a folding glycoprotein may become sequestered between the globular lectin domain and extended ERp57-binding arm domain of these chaperones, thereby minimizing interaction with other folding glycoproteins.

In an alternative dual binding model (Ware et al., 1995; Williams, 2006), Cnx and Crt possess an additional polypeptide binding site that recognizes nonnative protein conformers in a manner analogous to other molecular chaperones. Dual engagement of the lectin and polypeptide binding sites enhances chaperone-glycoprotein interactions relative to lectin binding alone (Stronge et al., 2001), and it permits suppression of glycoprotein aggregation through transient masking of exposed hydrophobic sites. Regulation of cyclic substrate interactions is accomplished for the lectin site as described above, and it is thought that the binding and release of ATP regulate polypeptide association because this nucleotide increases surface hydrophobic sites on Cnx and Crt and enhances suppression of substrate aggregation in vitro (Ihara et al., 1999; Saito et al., 1999; Brockmeier and Williams, 2006). Final release of the glycoprotein from the cycle occurs when all recognition sites for UGGT and for the 
polypeptide binding sites of $\mathrm{Cnx}$ and Crt are buried in the native glycoprotein.

Support for the lectin-only model comes from the finding that interactions between Cnx or Crt and many newly synthesized glycoproteins are lost when the formation of monoglucosylated oligosaccharides is blocked in glucosidase-deficient cells or in cells treated with glucosidase inhibitors (for lists, see Parodi, 2000; Danilczyk and Williams, 2001). Furthermore, studies with ribonuclease B and major histocompatibility complex (MHC) class I molecules both in vitro and in cells have indicated that $\mathrm{Cnx}$ and Crt do not recognize different conformational states of these glycoproteins directly, but rather their oligosaccharide chains are essential for chaperone association (Rodan et al., 1996; Zapun et al., 1997; Wearsch et al., 2004). Conversely, several studies have demonstrated that interactions of nascent glycoproteins with Cnx or Crt are maintained or only modestly diminished in cells either lacking glucosidases, treated with glucosidase inhibitors, or in which oligosaccharides have been removed through mutation (for reviews, see Danilczyk and Williams, 2001; Williams, 2006). Cnx and Crt have also been shown to associate preferentially with nonnative conformers of a variety of unglycosylated proteins in vitro, and they are capable of suppressing their aggregation (Ihara et al., 1999; Saito et al., 1999; Rizvi et al., 2004; Thammavongsa et al., 2005). These latter findings are consistent with the notion that Cnx and Crt can sense conformational states of substrates directly in a manner similar to other chaperones.

Given the conflicting results obtained with modulating glucosidase activity or by studying substrate interactions with Cnx and Crt in vitro, we decided to take an alternative approach of selectively ablating the lectin function of Crt and assessing the consequences by expressing the mutant chaperone in Crt-deficient cells. A convenient model glycoprotein for these studies is the MHC class I molecule, because Crt plays an important role in its biogenesis. Class I molecules consist of a glycosylated transmembrane heavy $(\mathrm{H})$ chain, the soluble $\beta_{2}$-microglobulin subunit $\left(\beta_{2} \mathrm{~m}\right)$, and an 8 - to 10-residue peptide ligand. Newly synthesized $\mathrm{H}$ chains bind rapidly to $\mathrm{Cnx}$ after which assembly with $\beta_{2} \mathrm{~m}$ occurs. At this point, the heterodimer enters a peptide loading complex (PLC) that also contains Crt, ERp57, tapasin and the peptide transporter associated with antigen processing (TAP). After peptide loading, assembled class I molecules are released from the PLC and exported to the cell surface where they are surveyed for the presence of foreign peptide antigens by cytotoxic T cells (for review, see Cresswell et al., 2005). As with other glycoproteins, class I glycans have been implicated in mediating interactions with lectin-chaperones, particularly Crt (Sadasivan et al., 1996; Radcliffe et al., 2002; Wearsch et al., 2004), although there have also been reports of glycan-independent interactions both in vitro and in cells (Danilczyk and Williams, 2001; Thammavongsa et al., 2005).

Class I molecules exhibit marked biosynthetic defects in Crt-deficient fibroblasts, including aberrantly rapid export from the ER (defective quality control), inefficient peptide loading, and reduced expression at the cell surface (Gao et al., 2002). Given this strong phenotype, we expressed lectindeficient point mutants of Crt into Crt-deficient cells, and we assessed their abilities to complement the functional defects in class I biogenesis. Remarkably, despite being demonstrably lectin deficient in these cells, the mutants fully complemented all class I biosynthetic defects, thereby demonstrating that Crt can exploit other modes of substrate interaction to effect its functions within living cells.

\section{MATERIALS AND METHODS}

\section{Cells, Antibodies, and Peptides}

Wild-type (K41) and Crt-deficient (K42) mouse embryonic fibroblasts were provided by Dr. M. Michalak (University of Alberta) (Nakamura et al., 2001), and they were maintained in RPMI 1640 medium containing $2 \mathrm{mM}$ glutamine, $10 \%$ fetal bovine serum (FBS), and antibiotics. K41 and K42 cells infected with Moloney virus were maintained in the same medium supplemented with 100 $\mu \mathrm{g} / \mathrm{ml}$ hygromycin B (Invitrogen, Carlsbad, CA).

The following antibodies to MHC class I molecules were used in this study: monoclonal antibody $(\mathrm{mAb}) 28-14-8 \mathrm{~S}$ that reacts with the $\mathrm{H}-2 \mathrm{D}^{\mathrm{b}}$ heavy chain regardless of $\beta_{2} \mathrm{~m}$ association (Ozato et al., 1980), mAb B22.249R1 that recognizes only $\beta_{2}$ m-associated $\mathrm{H}-2 \mathrm{D}^{\mathrm{b}}$ (Lemke et al., 1979), mAb Y3 specific for $\beta_{2} \mathrm{~m}$-associated $\mathrm{H}-2 \mathrm{~K}^{\mathrm{b}}$ (Jones and Janeway, 1981), and $\alpha 8$ serum that reacts with all conformational states of $\mathrm{H}-2 \mathrm{~K}^{\mathrm{b}}$ (provided by Dr. B. Barber, University of Toronto) (Smith et al., 1986). Anti-calreticulin antiserum was prepared by immunizing rabbits with recombinant mouse Crt lacking arm domain residues 223-286. Rabbit anti-tapasin antiserum directed against the C-terminal 20 amino acids of murine tapasin has been described previously (Suh et al., 1999). mAb 25-D1.16 that recognizes the complex of $\mathrm{H}-2 \mathrm{~K}^{\mathrm{b}}$ complexed with the ovalbumin-derived peptide SIINFEKL was provided by Dr. Ron Germain (National Institutes of Health, Bethesda, MD) (Porgador et al., 1997).

The $\mathrm{H}-2 \mathrm{D}^{\mathrm{b}}$ binding peptide ASNENMETM that corresponds to residues 366-374 of the influenza nucleoprotein and a peptide consisting of the Cterminal 20 amino acids of murine tapasin, SKEKATAASLTIPRNSKKSQ, were synthesized by the Alberta Peptide Institute (University of Alberta, Edmonton, $\mathrm{AB}$, Canada). The $\mathrm{H}-2 \mathrm{~K}^{\mathrm{b}}$ binding peptide SIINFEKL, corresponding to residues $257-264$ of ovalbumin, was provided by Dr. J. Gommerman (University of Toronto). Rabbit anti-mouse TAP1 antiserum was provided by Dr. Young Yang (Johnson \& Johnson Pharmaceutical Research and Development, San Diego, CA).

\section{Mouse Calreticulin cDNA Isolation and Mutagenesis}

Total RNA was extracted from mouse L cells and Crt cDNA was amplified using forward primer 5'-CGTAAGAAGCTTAAGGCCTGTGTGCCGCC-3', reverse primer 5'-GGCAGGTGGTGTGGCCTTCTAGAGCTAGC-3', and the ProSTAR Ultra HF reverse transcription-polymerase chain reaction system (Stratagene, La Jolla, CA). These primers introduced HindIII and XbaI restriction sites (underlined), respectively, for cloning into the pcDNA 3.1/Zeo expression vector (Invitrogen). Two lectin-deficient mouse Crt mutants were generated using the QuikChange mutagenesis kit (Stratagene). The following primers were used to convert a tyrosine at position 128 to alanine, Y128A, and also to introduce an SspI restriction site (underlined): forward 5'-CATGCATGGAGACTCAGAAgcTAATATTATGTTTGGTCCGGAC-3' and reverse 5'GTCCGGACCAAACATAATATTAgcTTATGAGTCTCCATGCATG-3'. The second mutant, D317A, was created using the following primers which also introduced an HaeII restriction site (underlined): forward 5'-GCTGTACTGGGCCTAGcgCTCTGGCAGGTCAAG-TCCG-3' and reverse 5'-CGGACTTGACCTGCCAGAGcgCTAGGCCCAGTACAGC-3'

The Moloney murine leukemia virus retroviral system was used for expressing wild-type and mutant mouse $\mathrm{Crt}$ in $\mathrm{K} 42 \mathrm{Crt}^{-/-}$cells. Using the preceding pcDNA 3.1/Zeo plasmids as templates, forward primer 5'-ATATGCGGCCGCGCCACCATGCTCCTTTCGGTGCCGCTCCTGCTT-3' and reverse primer 5'-ATATATGGATCCCTAGAGCTCATCCTTGGCTTGGCCAGGGGATTCT-3' were used to amplify wild-type and mutant Crt cDNA. These primers introduced NotI and BamHI restriction sites (underlined) respectively, for subcloning into the retroviral vector pQCXIH (Clontech, Mountain View, CA). The pQCXIH vector containing wild-type or mutant Crt cDNA $(2 \mu \mathrm{g})$ was mixed with $2 \mu \mathrm{g}$ each of vectors pVPack-VSV-G and pVPack-GP (Stratagene), along with $18 \mu$ l of FuGENE 6 (Hoffmann-La Roche, Mississauga, ON, Canada) and $100 \mu \mathrm{l}$ of serum-free Opti-MEM medium (Sigma-Aldrich, Oakville, ON, Canada), and the mixture was incubated for 30 min at room temperature before addition to the packaging cell line HEK293. Virus supernatant was harvested $36-48 \mathrm{~h}$ after transfection. In addition to viruses containing the various Crt plasmids, a virus containing an empty pQCXIH vector was also produced to be used in control infections of wildtype K41 and $\mathrm{Crt}^{-/-} \mathrm{K} 42$ cells. After infection of K41 or K42 cells with $2.5 \mathrm{ml}$ of viral supernatant and $8 \mu \mathrm{g} / \mathrm{ml}$ polybrene (Sigma-Aldrich), stable transformants were selected in $100 \mu \mathrm{g} / \mathrm{ml}$ hygromycin B and monitored for Crt expression by immunoblotting.

\section{Metabolic Labeling and Immunoisolation}

To isolate Crt and associated proteins or tapasin-containing peptide loading complexes, $6 \times 10^{6}$ virally infected $\mathrm{K} 41$ and K42 cells were starved for $30 \mathrm{~min}$ with Met-free RPMI 1640 medium and radiolabeled for $10 \mathrm{~min}$ in $2 \mathrm{ml}$ of medium containing $0.2 \mathrm{mCi}$ of $\left[{ }^{35} \mathrm{~S}\right] \mathrm{Met}(>1000 \mathrm{Ci} / \mathrm{mmol}$; GE Healthcare, Chalfont St. Giles, United Kingdom). The cells were lysed in digitonin lysis buffer [10 mM HEPES, pH 7.4, $150 \mathrm{mM} \mathrm{NaCl}, 1 \%$ digitonin, $10 \mathrm{mM}$ iodoacetamide, $60 \mu \mathrm{g} / \mathrm{ml}$ 4-(2-aminoethyl)benzenesulfonylfluoride hydrochloride, and $10 \mu \mathrm{g} / \mathrm{ml}$ each of leupeptin, antipain, and pepstatin], and then they were subjected to immunoisolation with anti-Crt or anti-tapasin antiserum for $2 \mathrm{~h}$. To assess the stability of Crt-substrate complexes, a second set of lysates was 
incubated for $45 \mathrm{~min}$ before immunoisolation with anti-Crt antiserum. In all cases, immune complexes were recovered by incubation for $1 \mathrm{~h}$ with $30 \mu \mathrm{l}$ of protein A agarose. The beads were washed three times with $10 \mathrm{mM}$ HEPES, pH 7.4, $150 \mathrm{mM} \mathrm{NaCl}, 0.2 \%$ digitonin, eluted in SDS-polyacrylamide gel electrophoresis (PAGE) sample buffer, and analyzed by reducing SDS-PAGE (10\% gels) followed by fluorography.

For pulse-chase experiments, $1 \times 10^{6}$ virally infected K41 or K42 cells in 60-mm plates were incubated for $20 \mathrm{~min}$ in Met-free RPMI 1640 medium, and then they were radiolabeled for $10 \mathrm{~min}$ in $1 \mathrm{ml}$ of the same medium containing $0.1 \mathrm{mCi}$ of $\left[{ }^{35} \mathrm{~S}\right] \mathrm{Met}(>1000 \mathrm{Ci} / \mathrm{mmol}$; GE Healthcare). The labeling medium was removed, and the cells were chased for various times in RPMI 1640 medium containing $1 \mathrm{mM}$ Met. To isolate Crt and associated proteins, cells were first lysed at $4^{\circ} \mathrm{C}$ in digitonin lysis buffer, and then they were subjected to a rapid immunoisolation procedure in which lysates were incubated for $30 \mathrm{~min}$ with anti-calreticulin antiserum followed by a 1-h incubation with protein A-agarose. Beads were washed three times rapidly with $10 \mathrm{mM}$ HEPES, $\mathrm{pH} 7.4,150 \mathrm{mM} \mathrm{NaCl}, 0.2 \%$ digitonin, and then isolated proteins were analyzed by SDS-PAGE (10\% gels) and fluorography. To isolate class I molecules after pulse-chase experiments, cells were lysed at $4^{\circ} \mathrm{C}$ in NP-40 lysis buffer (containing $1 \% \mathrm{NP}-40$ instead of $1 \%$ digitonin). Lysates were first incubated for $2 \mathrm{~h}$ with a combination of mAbs 28-14-8S and B22.249R1 followed by a 1-h incubation with $30 \mu \mathrm{l}$ of protein $\mathrm{A}$-agarose to recover $\mathrm{H}-\mathrm{D}^{\mathrm{b}}$ molecules. The cleared lysates were then treated with anti- 8 serum and protein $\mathrm{A}$-agarose to isolate $\mathrm{H}-2 \mathrm{~K}^{\mathrm{b}}$ molecules. The beads were washed three to four times in 10 mM HEPES, pH 7.4, $150 \mathrm{mM}$ $\mathrm{NaCl}, 1 \% \mathrm{NP}-40$, and then class I molecules were eluted by heating for $5 \mathrm{~min}$ at $70^{\circ} \mathrm{C}$ in $0.1 \mathrm{M}$ citrate buffer, $\mathrm{pH} 6.0$, containing $0.2 \%$ SDS. Samples were diluted to $0.1 \%$ SDS, and then they were digested with $20-30 \mathrm{U}$ of endo- $\beta$ - $N$-acetyl glucosaminidase $\mathrm{H}$ (endo $\mathrm{H}$; New England Biolabs, Ispwich, MA) before analysis by SDS-PAGE (10\% gel) and detection by fluorography.

\section{Flow Cytometry}

Virally-infected K41 and K42 cells were grown to 50\% confluence, removed from plates by trypsinization, centrifuged and $3.5 \times 10^{5}$ cells per sample were incubated on ice for $20 \mathrm{~min}$ in $100 \mu \mathrm{l}$ of fluorescence-activated cell sorting (FACS) buffer (Hank's balanced salt solution with $0.5 \%$ bovine serum albumin) containing $1.5 \mu \mathrm{g}$ of $\mathrm{mAb}$ Y3 or B22-249.R1. Cells were washed and incubated for $30 \mathrm{~min}$ on ice with $0.5 \mu \mathrm{g}$ of phycoerythrin-conjugated goat anti-mouse IgG in $0.1 \mathrm{ml}$ of FACS buffer. Cells were then washed and fixed in $300 \mu \mathrm{l}$ of phosphate-buffered saline (PBS) containing $0.5 \%$ paraformaldehyde. Samples were analyzed using a BD FACSCalibur Flow cytometer (BD Biosciences, Franklin Lakes, NJ). For experiments measuring the peptide receptivity of class I molecules on the cell surface, cells were plated at $50 \%$ confluence, and $6 \mathrm{~h}$ later, the medium was removed and replaced with either serum-free RPMI 1640 or serum-free RPMI 1640 supplemented with $10 \mu \mathrm{M}$ SIINFEKL + $10 \mu \mathrm{M}$ ASNENMETM peptides. After overnight incubation, samples were analyzed by flow cytometry as described above.

\section{Antigen Presentation Assay}

Virally transfected K41 or K42 cells $\left(2 \times 10^{6}\right)$ were resuspended in $100 \mu$ of Amaxa nucleofection " $V$ " solution and mixed with $3 \mu \mathrm{g}$ plasmid DNA encoding green fluorescent protein (GFP) fused to ubiquitin and SIINFEKL peptide (provided by Dr. Jacques Neefjes, Netherlands Cancer Institute, Amsterdam, The Netherlands; Neijssen et al., 2005). Electroporation was conducted using a Nucleofector I (Amaxa Biosystems, Cologne, Germany) set to program T-30. Subsequently, cells were resuspended in prewarmed RPMI 1640 medium containing 10\% FBS and dispensed into a six-well plate. After $24 \mathrm{~h}$, cells were harvested and prepared for flow cytometry using $\mathrm{K}^{\mathrm{b}}$-SIINFEKLspecific mAb 25-D1.16 followed by Alexa Fluor 642 anti-mouse antibody (Ab). Analysis was undertaken on an FACS Canto (BD Biosciences) using FACS Diva software with at least 40,000 events being collected. Samples were gated against low, medium and high GFP fluorescence to which the corresponding mAb 25-D1.16 fluorescence could be correlated.

\section{RESULTS}

\section{Expression and Substrate Interaction Properties of Lectin-deficient Crt Mutants}

We and others have shown that rabbit Crt residues Y109, K111, D135, Y128, and D317 are crucial for the lectin function of this molecular chaperone. Substituting alanine individually at positions Y109, K111, Y128, and D317 resulted in a complete loss of $\left[{ }^{3} \mathrm{H}\right] \mathrm{Glc}_{1} \mathrm{Man}_{9} \mathrm{GlcNAc}_{2}$ binding to immobilized glutathione s-transferase-Crt mutants (Thomson and Williams, 2005). Independent studies using isothermal titration calorimetry also revealed that mutants Y109F, D135L, and D317A exhibited no detectable binding to the trisaccharide Glc $\alpha 3$ Man $\alpha 2$ Man $\alpha$ Me (Kapoor et al., 2004; Gopalakrishnapai et al., 2006). None of these point mutations altered Crt structure as evidenced by circulardichroism analysis or sensitivity to protease digestion. Mouse Crt is $96 \%$ identical to rabbit Crt and all of the residues important for lectin function are conserved. We mutated residues Y128 and D317 to alanine in mouse Crt, and we confirmed that the mutations ablated lectin function in direct oligosaccharide binding assays (data not shown). We then expressed these mutants along with wild-type mouse $\mathrm{Crt}$ in $\mathrm{K} 42 \mathrm{Crt}^{-/-}$mouse embryonic fibroblasts using a Moloney virus expression system. As shown in Figure 1A, stable cell lines were established after viral infection, with steady-state expression of wild type and mutant Crt at levels close to that observed in $\mathrm{K} 41 \mathrm{Crt}^{+/+}$fibroblasts. Furthermore, the virally expressed Crt proteins were synthesized at rates similar to that of wild-type Crt in K41 cells (Figure 1, B and C, arrows). As a control for any effects of viral infection, cells designated K41 $\mathrm{Crt}^{+/+}$and $\mathrm{K} 42 \mathrm{Crt}^{-/-}$were infected with virus that was packaged with an empty expression vector. These were used

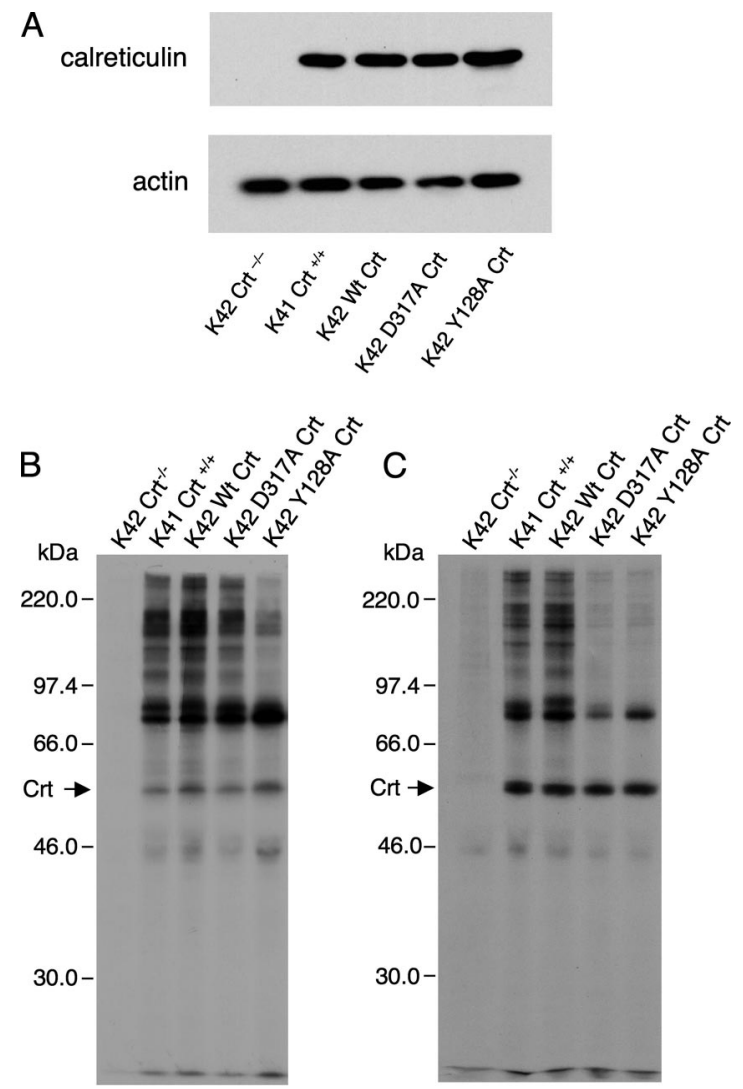

Figure 1. Wild-type and mutant Crt are expressed in Crt-deficient cells and associate with newly synthesized proteins. (A) Crt-deficient murine fibroblasts (K42 cells) were infected with virus encoding the indicated wild-type $(\mathrm{Wt})$ and oligosaccharide-binding deficient Crt proteins (Y128A and D317A). In addition, cells designated $\mathrm{K} 42 \mathrm{Crt}^{-1-}$ and $\mathrm{K} 41 \mathrm{Crt}^{+/+}$were infected with virus packaged with an empty expression vector. Cells $\left(10^{6}\right)$ were lysed in NP-40 lysis buffer, proteins were separated by SDS-PAGE (10\% gel), and Crt was detected by immunoblotting. Actin was also immunoblotted to serve as a gel loading control. (B) Cells transfected with various Crt constructs (or empty vector) were radiolabeled for $10 \mathrm{~min}$ with $\left[{ }^{35} \mathrm{~S}\right]$ Met, lysed in digitonin lysis buffer, and subjected to immunoisolation with anti-Crt antiserum. Crt-associated proteins were separated by SDS-PAGE and visualized by fluorography. (C) The experiment in B was repeated except that before immunoisolation, the lysates were incubated on ice for $45 \mathrm{~min}$. Exposures, $30 \mathrm{~h} \mathrm{(B)}$ and $72 \mathrm{~h}(\mathrm{C})$. 
in all subsequent experiments, and they were indistinguishable from uninfected K41 and K42 cells (data not shown).

We demonstrated previously that lectin-deficient rabbit Crt possessing either the Y128A or D317A mutation was fully capable of interacting with a nonglycosylated protein in vitro and suppressing its thermally induced aggregation through polypeptide-based interactions (Thomson and Williams, 2005). To test whether these mutations in the context of mouse Crt possessed the ability to associate with newly synthesized proteins in cultured cells, virally transfected cells were radiolabeled with $\left[{ }^{35} \mathrm{~S}\right] \mathrm{Met}$ and Crt complexes with newly synthesized proteins were recovered from digitonin lysates by immunoisolation with anti-Crt antiserum (Figure 1B). Many Crt-protein complexes were recovered from $\mathrm{K} 41 \mathrm{Crt}^{+/+}$cells as well as from K42 $\mathrm{Crt}^{-/-}$cells transfected with wild-type Crt. No complexes were recovered from $\mathrm{K} 42 \mathrm{Crt}^{-/-}$cells, indicating the specificity of the immunoisolation procedure. As has been observed previously, proteins associated with Crt were typically larger than $\sim 40 \mathrm{kDa}$, with two prominent species at 76 and $84 \mathrm{kDa}$ (Peterson et al., 1995; Danilczyk and Williams, 2001). A similar pattern of associated proteins was recovered with the D317A mutant and the Y128A mutant, although the abundance of a number of proteins was reduced in the latter mutant. This was not due to any inherent differences between the two mutants, but rather it reflects the fact that polypeptide-based interactions between Crt and associated proteins are rather labile (see below) and the intensities of associated proteins vary from experiment to experiment. For example, no major difference in the abundance of associated proteins was observed when complexes with wild-type Crt and Y128A Crt were compared in Figure 2 (bottom). These findings suggest that in the absence of lectin-oligosaccharide binding, mouse Crt retains the ability to associate with many newly synthesized proteins through polypeptide-based interactions, a result that is in accordance with similar experiments on Cnx (Danilczyk and Williams, 2001).

To confirm that the Crt Y128A and D317A mutants lack lectin functionality within K42 cells, the radiolabeling experiment was repeated, but in this case the digitonin lysates were incubated for $45 \mathrm{~min}$ before immunoisolation with anti-Crt antiserum. Previous studies with $\mathrm{Cnx}$ have shown that many Cnx-containing complexes are labile in the absence of lectin-oligosaccharide interactions and that they will dissociate if not recovered promptly (Danilczyk and Williams, 2001). As shown in Figure 1C, most protein interactions with the two mutants were either lost or severely diminished after the 45-min incubation in contrast to wildtype Crt in K41 or K42 cells, which exhibited more stable association with newly synthesized proteins. Thus, the Crt Y128A and Crt D317A mutants seem to lack lectin functionality both in vitro and in cultured cells.

It has been shown previously that ER chaperones can be detected in large, stable complexes with other components of the ER folding machinery (Tatu and Helenius, 1997; Meunier et al., 2002). Presumably, Crt would not interact with components of this folding machinery through lectinbased interactions. Thus, it was important to determine whether the newly synthesized proteins coisolated with Crt, and shown to exhibit labile interactions with the lectindeficient mutants, were indeed substrates that interact transiently with the chaperone during folding or whether they were stably associated components of the folding machinery. To address this issue, cells expressing wild-type or lectin-deficient Crt were subjected to pulse-chase radiolabeling, and Crt-associated proteins were isolated at each time point. Because the efficiency of recovery of different Crt-

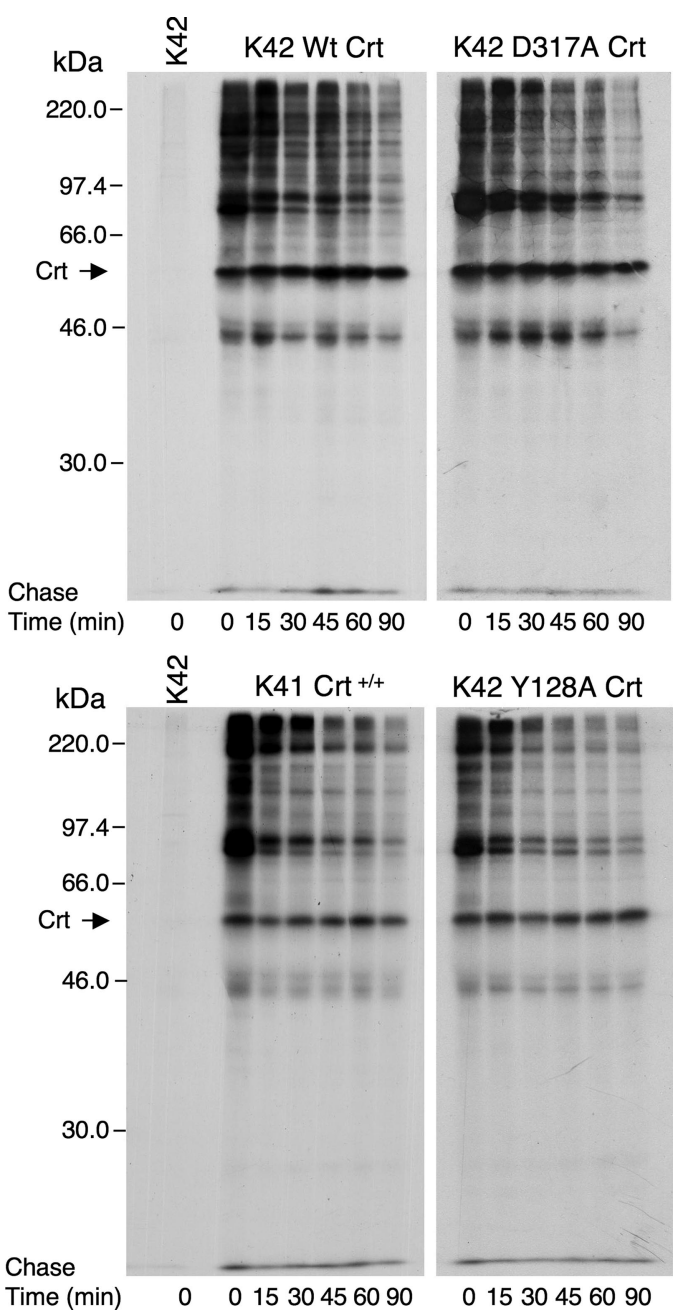

Figure 2. Interaction kinetics of wild-type and mutant $\mathrm{Crt}$ with newly synthesized proteins. K41 and K42 cells expressing the indicated Crt proteins were radiolabeled with $\left.{ }^{35} \mathrm{~S}\right]$ Met for $10 \mathrm{~min}$, and then they were chased in medium containing unlabeled Met for the times shown. At each time point, cells were lysed in digitonin lysis buffer, and then Crt and associated proteins were recovered by immunoisolation with anti-Crt antiserum. Radiolabeled proteins were separated by SDS-PAGE and visualized by fluorography. The results depicted in the top two panels were obtained from a single experiment and those in the bottom two panels were obtained in another experiment.

associated proteins varied somewhat from experiment to experiment, we compared the patterns of associated proteins for wild-type Crt and the D317A mutant in one experiment (Figure 2, top) and for wild-type Crt and the Y128A mutant in a second experiment (Figure 2, bottom). In both experiments, Crt-deficient K42 cells were included as a control for the specificity of the immunoisolation, and, as expected, no proteins were recovered (Figure 2, K42 lanes). For all four cell lines, although the intensities of several Crtassociated proteins seemed unaltered during the chase, the majority of complexes dissociated extensively and at various rates over the $90-\mathrm{min}$ chase period. This is consistent with previous studies that documented transient association of both Cnx and Crt during the folding of diverse glycoprotein substrates (David et al., 1993; Peterson et al., 1995). Furthermore, both the patterns of associated proteins and their dissociation kinetics seemed to be remarkably similar when 
Figure 3. Wild-type and lectin-deficient Crt normalize surface expression of MHC class I molecules in $\mathrm{Crt}^{-/-} \mathrm{K} 42$ cells. (A) K42 cells stably expressing wild-type Crt or lectin-deficient mutants were incubated with $\mathrm{mAbs} \mathrm{Y}-3$ or B22.249R1 to detect cell surface $\mathrm{H}-2 \mathrm{~K}^{\mathrm{b}}$ and $\mathrm{H}-2 \mathrm{D}^{\mathrm{b}}$ molecules, respectively. Cells were then incubated with phycoerythrin-conjugated goat anti-mouse IgG and analyzed by flow cytometry. K41 and K42 cells transfected with empty vector were also subjected to this analysis. As a negative control, cells were stained with secondary antibody alone. (B) Mean fluorescence values are plotted as percentages relative to $\mathrm{Crt}^{+/+} \mathrm{K} 41$ cells. Error bars represent the $\mathrm{SE}$ values from three independent experiments.
A

Surface $\mathrm{H}-2 \mathrm{~K}^{\mathrm{b}}$

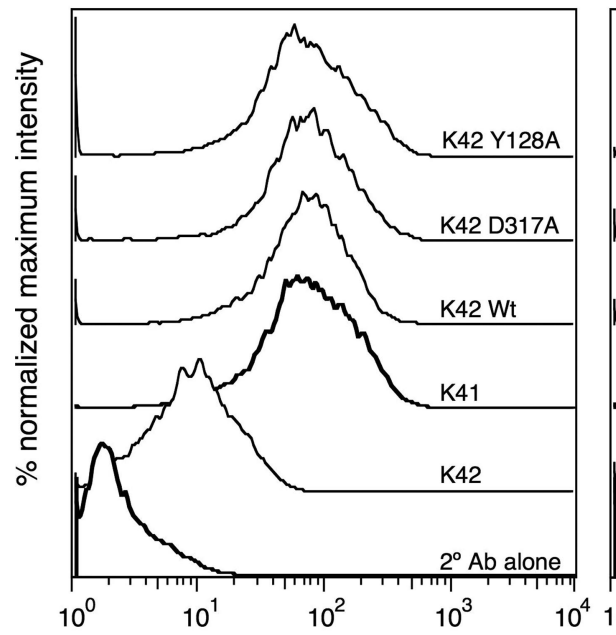

Fluorescence Intensity

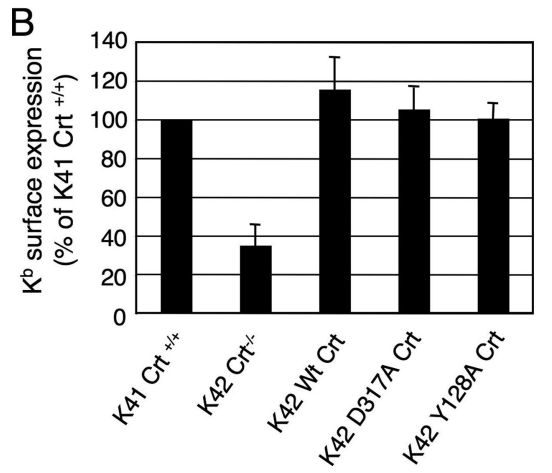

Surface $\mathrm{H}-2 \mathrm{D}^{\mathrm{b}}$

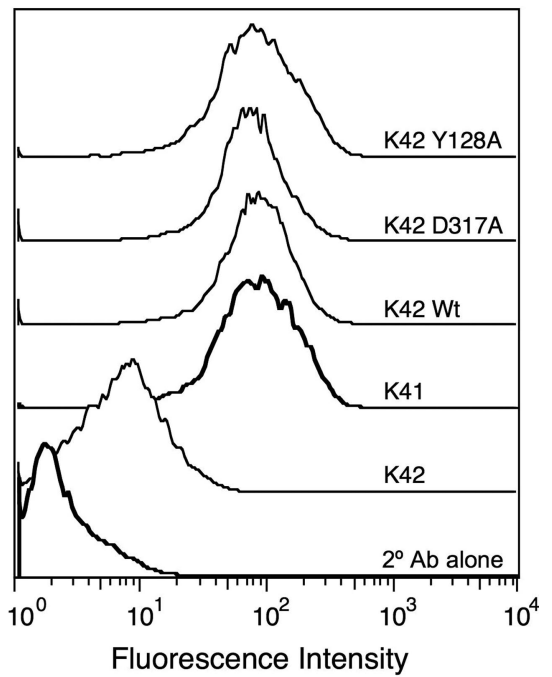

Fluorescence Intensity

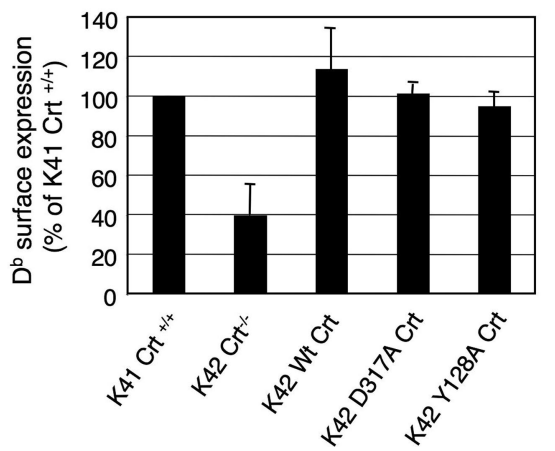

wild-type Crt and the D317A mutant were compared (Figure 2, top) and when wild-type Crt and the Y128A mutant were compared (Figure 2, bottom). These findings suggest that the majority of newly synthesized proteins associated with wild-type and lectin-deficient $\mathrm{Crt}$ are indeed substrates and that their dissociation from the mutant chaperones occurs at near normal rates despite the absence of any lectinoligosaccharide interaction.

\section{Lectin-deficient Crt Restores Normal Peptide Loading and Class I Surface Expression in $\mathrm{Crt}^{-1-}$ Cells}

Crt deficiency is associated with a three- to fourfold reduction in expression of class I molecules at the cell surface, a consequence of defective intracellular loading of class I molecules with stabilizing peptides (Gao et al., 2002). This reduction in surface expression can be seen in Figure 3 where the levels of surface class I H-2 $\mathrm{K}^{\mathrm{b}}$ and $\mathrm{H}-2 \mathrm{D}^{\mathrm{b}}$ molecules on $\mathrm{K}_{4} \mathrm{Crt}^{+/+}$and $\mathrm{K} 42 \mathrm{Crt}^{-/-}$cells were compared by flow cytometry. In $\mathrm{K} 42$ cells, both $\mathrm{K}^{\mathrm{b}}$ and $\mathrm{D}^{\mathrm{b}}$ were expressed at about one third the level of that observed in K41 cells. Normal expression of both molecules was restored upon transfection of K42 cells with wild-type Crt (Figure 3, K42 $\mathrm{Wt}$ ). To determine whether the lectin site of Crt is important for restoring normal expression of class I molecules, the surface expression of $\mathrm{K}^{\mathrm{b}}$ and $\mathrm{D}^{\mathrm{b}}$ were examined in $\mathrm{K} 42$ cells transfected with the Y128A and D317A lectin-deficient mutants. Both mutant proteins restored the surface expression of $\mathrm{K}^{\mathrm{b}}$ and $\mathrm{D}^{\mathrm{b}}$ to the levels observed in cells expressing wild-type Crt. This was remarkable given previous studies

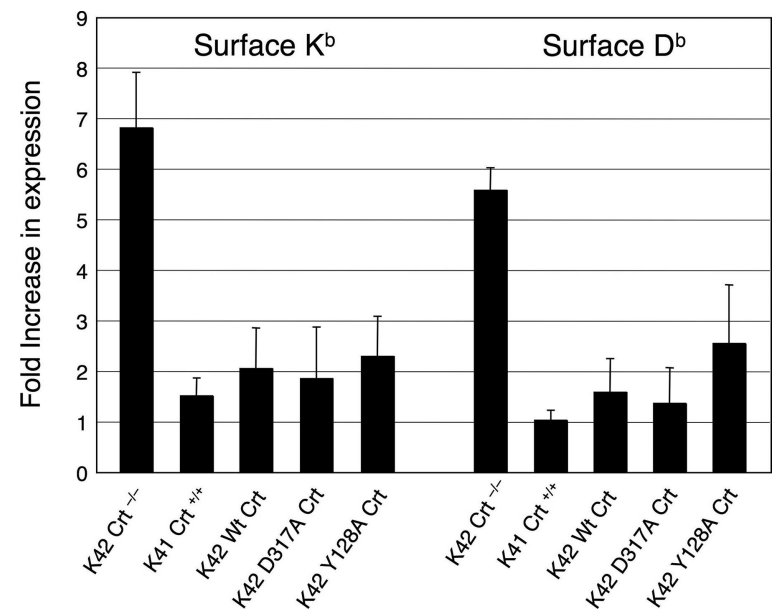

Figure 4. Peptide loading of class I molecules is promoted by wild-type and lectin-deficient Crt. Stably transfected K41 and K42 cells expressing the indicated Crt proteins were incubated with the $\mathrm{K}^{\mathrm{b}}$ binding peptide SIINFEKL and the $\mathrm{D}^{\mathrm{b}}$ binding peptide NP366374 overnight and subsequently evaluated for cell surface class I expression by flow cytometry by using mAbs Y3 and B22-249.R1. Results are shown as the -fold increase in expression (mean fluorescence value) relative to cells incubated without peptide. Error bars represent the SE values from three independent experiments. 


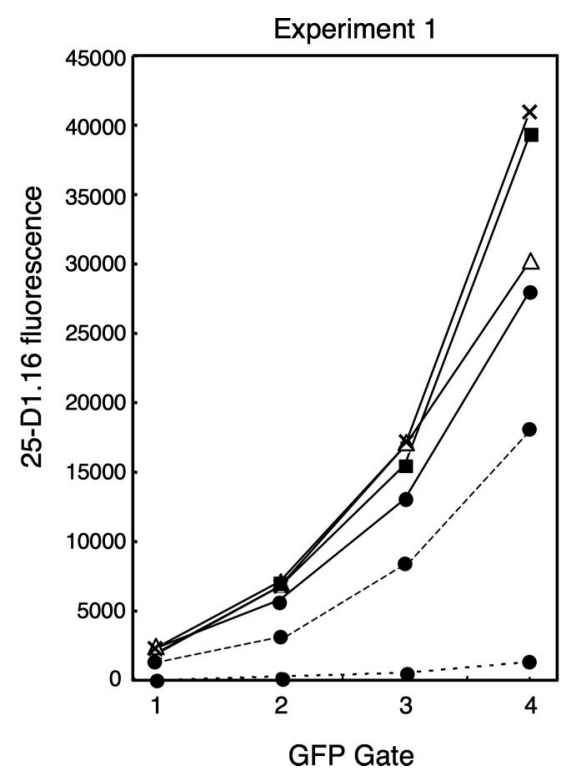

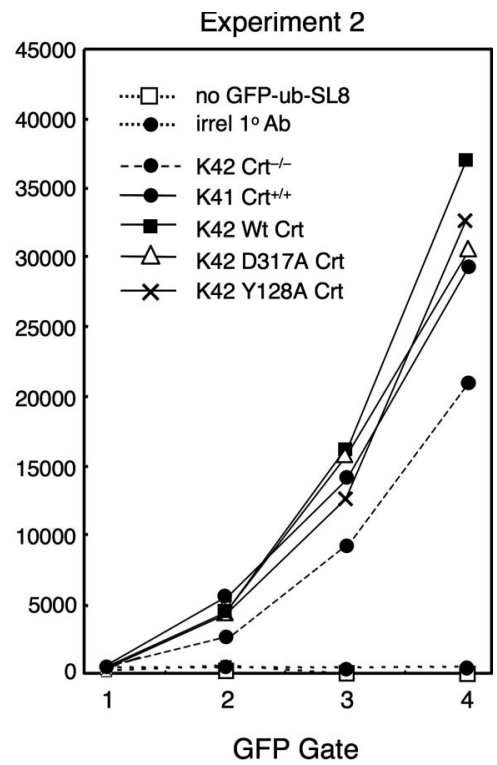

Figure 5. Wild-type and lectin-deficient Crt enhance the presentation of a specific ovalbumin peptide by $\mathrm{H}-2 \mathrm{~K}^{\mathrm{b}}$ molecules. K41 cells and $\mathrm{K} 42$ cells expressing the indicated Crt proteins were transiently transfected with a plasmid encoding GFP fused to ubiquitin followed by the ovalbumin-derived sequence SIINFEKL. After $24 \mathrm{~h}$, cells were analyzed by flow cytometry by using mAb 25D1.16, which recognizes the SIINFEKL peptide in complex with $\mathrm{H}-2 \mathrm{~K}^{\mathrm{b}}$ molecules, followed by Alexa Fluor $642-$ conjugated anti-mouse $\mathrm{Ab}$. Samples were gated against low, medium, and high GFP fluorescence (GFP gates 1-4) and plotted against the corresponding mean 25D1.16 fluorescence. Two separate experiments are shown and include controls lacking plasmid or in which an isotype-matched primary antibody replaced mAb 25D1.16. suggesting that lectin-oligosaccharide interactions are the principal means whereby Crt associates with assembling class I molecules (Harris et al., 1998; Radcliffe et al., 2002; Wearsch et al., 2004).

We next examined whether lectin-deficient Crt is capable of promoting peptide loading onto class I molecules. Class I molecules that do not acquire stabilizing peptide during their biogenesis are capable of reaching the cell surface but rapidly disassemble into constituent subunits that are not reactive with conformation-sensitive $\mathrm{mAb}$. These transient, peptide-receptive class I molecules can be stabilized by the addition of exogenous peptides to the culture medium, resulting in a substantial upregulation of surface expression (Townsend et al., 1989). This phenomenon is illustrated in Figure 4 wherein $\mathrm{Crt}^{-1-}$ K42 cells exhibited a five- to sevenfold increase in surface expression of $\mathrm{K}^{\mathrm{b}}$ and $\mathrm{D}^{\mathrm{b}}$ molecules following overnight incubation with their respective peptide ligands, SIINFEKL and ASNENMETM. In contrast, only a modest 1.5- to 2-fold increase in surface expression of these molecules was observed when $\mathrm{Crt}^{+/+} \mathrm{K} 41$ cells or $\mathrm{K} 42$ cells transfected with wild-type Crt were incubated with peptide. This reflects the smaller population of peptide-receptive class I molecules that are produced in cells possessing Crt. Remarkably, when K42 cells expressing either the lectindeficient Y128A and D317A Crt mutant were incubated with peptide ligands, the extent of surface $\mathrm{K}^{\mathrm{b}}$ and $\mathrm{D}^{\mathrm{b}}$ upregulation was approximately twofold, similar to that observed in cells expressing wild-type Crt. These findings indicate that although the Y128A and D317A Crt mutants lack the ability to bind monoglucosylated oligosaccharide, they retain the ability to promote the loading of peptides onto assembling class I molecules.

We subsequently confirmed these results using an antigen presentation assay in which a specific class I-binding peptide is produced in the cytosol and delivered to class I molecules in the ER through the normal antigen processing machinery. In this assay, a chimeric molecule consisting of green fluorescent protein fused to ubiquitin followed by the $\mathrm{K}^{\mathrm{b}}$ binding peptide SIINFEKL (GFP-Ub-SIINFEKL) is transiently expressed in K41 and K42 cells as well as the various K42 transfectants. The SIINFEKL peptide is released in the cytosol by ubiquitin hydrolase activity (Neijssen et al., 2005) and, following its delivery to the ER and loading onto $\mathrm{K}^{\mathrm{b}}$ molecules, the $\mathrm{K}^{\mathrm{b}}$-SIINFEKL complex is detected at the cell surface by using $\mathrm{mAb} 25-\mathrm{D} 1.16$. The relative amount of fusion protein and consequently SIINFEKL peptide produced in the transfectants is proportional to the intensity of GFP fluorescence. Thus, by gating on different levels of GFP fluorescence, the surface expression of $\mathrm{K}^{\mathrm{b}}$-SIINFEKL complexes in the transfectants can be compared as a function of peptide concentration. As shown in two separate experiments in Figure 5, wild-type K41 cells consistently expressed more $\mathrm{K}^{\mathrm{b}}$-SIINFEKL complexes at the cell surface than did $\mathrm{Crt}^{-1-}$ K42 cells. This was the case at all but the lowest levels of fusion protein expression (Figure 5, GFP gates 1-4), confirming previous results obtained with various $\mathrm{T}$ cellbased assays (Gao et al., 2002). The antigen presentation defect of K42 cells could be overcome by expressing wildtype Crt in these cells or either of the lectin-deficient Crt mutants (Figure 5, compare K42 with K42 Wt Crt, Y128 Crt, and D317A Crt). Thus, using methods that detect both general and antigen-specific peptide loading, it is apparent that Crt does not require a functional lectin site to promote efficient peptide loading of class I molecules.

\section{Lectin-deficient Crt Is Incorporated into the Peptide Loading Complex}

The loading of class I molecules with stabilizing peptides occurs in the ER after the incorporation of class I into the PLC. This complex consists of the class I H chain- $\beta_{2} \mathrm{~m}$ heterodimer, the TAP peptide transporter, tapasin (which bridges the interaction between class I and TAP), the thiol oxidoreductase ERp57 (which forms a mixed disulfide with tapasin), and Crt (Cresswell et al., 2005). Presumably, the ability of lectin-deficient Crt mutants to promote peptide loading of class I molecules should reflect their inclusion within the PLC. To test this, the composition of PLCs from the various cell lines was determined by immunoisolation from digitonin lysates of unlabeled or radiolabeled cells with anti-tapasin antiserum and detection of components by immunoblotting or by fluorography, respectively. As shown in Figure 6A, PLCs recovered with anti-tapasin antiserum from lysates of $\mathrm{K} 41 \mathrm{Crt}^{+/+}$cells or K42 cells transfected with wild-type Crt also contained the TAP transporter, Crt and ERp57. Examination of corresponding PLCs from radiola- 
A

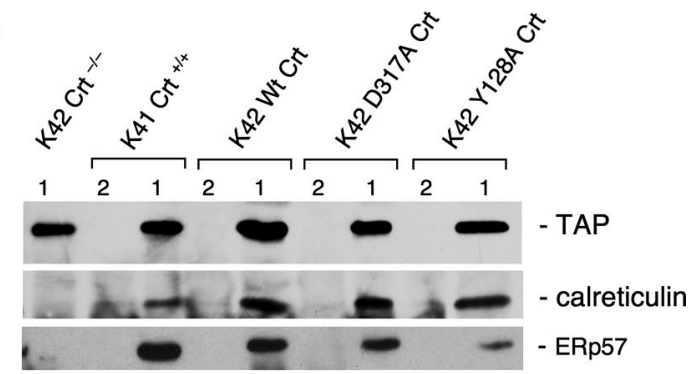

B

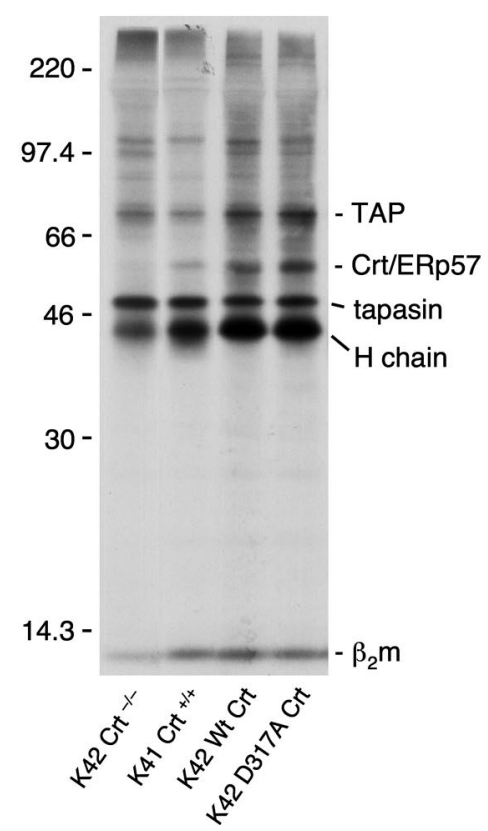

Figure 6. Association of lectin-deficient Crt with members of the peptide loading complex. (A) The indicated cell lines were lysed in digitonin lysis buffer and then subjected to immunoisolation with either anti-tapasin antiserum (lanes 1) or preimmune serum (lanes 2). Immune complexes adsorbed on protein A beads were dissociated with $100 \mu \mathrm{M}$ of the C-terminal tapasin peptide used to raise the antiserum. Eluted proteins were separated by SDS-PAGE and immunoblotted with antibodies directed against Crt, ERp57, and the TAP peptide transporter. Note that the high background in the Crt panel is due to residual Ig heavy chain from the anti-tapasin antiserum $(50 \mathrm{kDa})$, which migrates just below Crt $(60 \mathrm{kDa})$. (B) The indicated cells were radiolabeled with $\left[{ }^{35} \mathrm{~S}\right] \mathrm{Met}$ for $30 \mathrm{~min}$, incubated on ice for $10 \mathrm{~min}$ with $20 \mathrm{mM} \mathrm{N}$-ethylmaleimide in PBS, lysed in digitonin lysis buffer, and then subjected to immunoisolation with anti-tapasin antiserum. Isolated proteins were resolved on a nonreducing $10-15 \%$ gradient SDS-PAGE gel.

beled cell lysates revealed the additional presence of tapasin, class I heavy chain, and $\beta_{2} \mathrm{~m}$ (Figure 6B). Consistent with their ability to restore peptide loading in K42 cells, both the Y128A and D317A Crt mutants were readily detectable within the PLC as were all other components (Figure 6, A and $\mathrm{B}$ ). Thus, an intact lectin site is not required for recruitment of Crt to the PLC.

As expected, the PLC from $\mathrm{K} 42 \mathrm{Crt}^{-/-}$cells lacked Crt, but it also lacked ERp57 (Figure 6A) and exhibited reduced heavy chain and $\beta_{2} \mathrm{~m}$ levels (Figure 6B). The lack of ERp57 was not consistent with previous findings in which ERp57 was shown to be present in the PLC recovered from K42 cells with anti-TAP antiserum (Gao et al., 2002). In multiple experiments, we have found that the amount of ERp57 recovered in the PLC of $\mathrm{Crt}^{-/-} \mathrm{K} 42$ cells is variable, with better recovery in coimmunoprecipitates using anti-TAP versus anti-tapasin antiserum or when $\mathrm{N}$-ethylmaleimide is included to stabilize the tapasin-ERp57 mixed disulfide by inhibiting disulfide exchange (Cresswell et al., 2005). The reason for the variability is unclear, but it probably reflects the relative fragility of the PLC lacking Crt compared with that in which Crt is incorporated either as a native protein or a lectin-deficient mutant.

\section{Lectin-deficient Crt Complements the Rapid Intracellular Transport Phenotype of Class I Molecules in Crt-deficient Cells}

Class I molecules that fail to acquire a stabilizing peptide are subject to ER quality control, and they are exported slowly along the secretory pathway (Townsend et al., 1989; Degen et al., 1992). Crt seems to play a role in this quality control process because class I molecules that fail to acquire stabilizing peptides in Crt-deficient cells are exported rapidly from the ER (Gao et al., 2002). This transport behavior is depicted in Figure 7 in which ER-to-Golgi transport rates of $\mathrm{K}^{\mathrm{b}}$ and $\mathrm{D}^{\mathrm{b}}$ molecules were determined by monitoring the kinetics at which their Asn-linked oligosaccharides are processed to complex forms that are resistant to digestion with endoglycosidase $\mathrm{H}$ (endo $\mathrm{H}$ ). $\mathrm{K}^{\mathrm{b}}$ and $\mathrm{D}^{\mathrm{b}}$ were exported with half times of $\sim 27$ and $\sim 80 \mathrm{~min}$, respectively, in $\mathrm{K}_{41} \mathrm{Crt}^{+/+}$ cells or $\mathrm{K} 42$ cells transfected with wild-type Crt. In contrast, the corresponding rates in $\mathrm{Crt}^{-/-} \mathrm{K} 42$ cells were considerably more rapid, $\sim 12$ and $53 \mathrm{~min}$, respectively (Figure $7, \mathrm{~A}$ and B).

To determine whether Crt's lectin function is required to influence the transport behavior of class I molecules, the ER-to-Golgi transport kinetics of $\mathrm{K}^{\mathrm{b}}$ and $\mathrm{D}^{\mathrm{b}}$ molecules were measured in K42 cells expressing the Y128A and D317A lectin-deficient $\mathrm{Crt}$ mutants. Consistent with the recruitment of these mutants to the PLC, they were just as effective as wild-type $\mathrm{Crt}$ in normalizing the export kinetics of both $\mathrm{K}^{\mathrm{b}}$ and $\mathrm{D}^{\mathrm{b}}$ molecules. Indeed, in cells expressing D317A Crt, $\mathrm{K}^{\mathrm{b}}$ and $\mathrm{D}^{\mathrm{b}}$ were exported with half times of 26 and $83 \mathrm{~min}$, respectively, compared with $\sim 27$ and $\sim 80 \mathrm{~min}$ in K41 $\mathrm{Crt}^{+/+}$cells or K42 cells transfected with wild-type Crt. For the Y128A mutant, the corresponding half time for $\mathrm{D}^{\mathrm{b}}$ was similar to wild-type Crt at 90 min, whereas that for $\mathrm{K}^{\mathrm{b}}$ was somewhat slower than wild-type $\mathrm{Crt}$ at $40 \mathrm{~min}$ (Figure 7B).

\section{DISCUSSION}

The class I peptide loading complex is a complex structure that is stabilized by multiple interactions between its constituent components. At the center of the complex is tapasin, which interacts with both peptide-deficient class I molecules and the polytopic TAP peptide transporter, bridging the two. Tapasin is also linked to the thiol oxidoreductase ERp57 through a stable disulfide linkage, and this tapasin-ERp57 subcomplex has been shown to promote the loading of peptides into the class I binding groove and their subsequent editing to favor peptides of higher affinity or slower off-rate (Wearsch and Cresswell, 2007). Crt is also a component of the PLC, and it associates noncovalently with both the class I H chain and with ERp57.

How Crt functions to promote peptide loading onto class I molecules is unclear. From the data in Figure 6, it is apparent that it stabilizes some components of the peptide loading complex, such as ERp57, which is directly involved in peptide loading and editing (Wearsch and Cresswell, 2007). Crt has also been shown to bind to peptides transported into the ER by TAP (Spee and Neefjes, 1997), and this may protect peptides from excessive trimming by ER amin- 
A
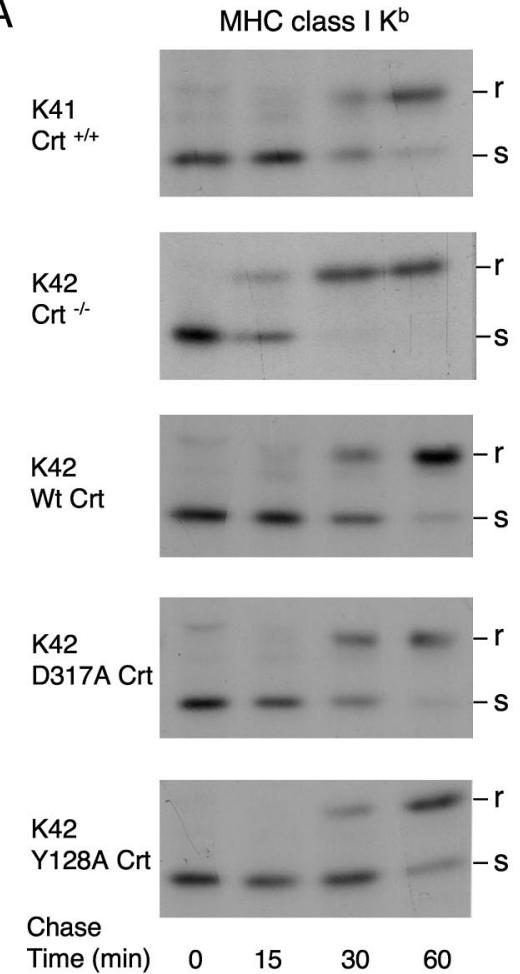

B

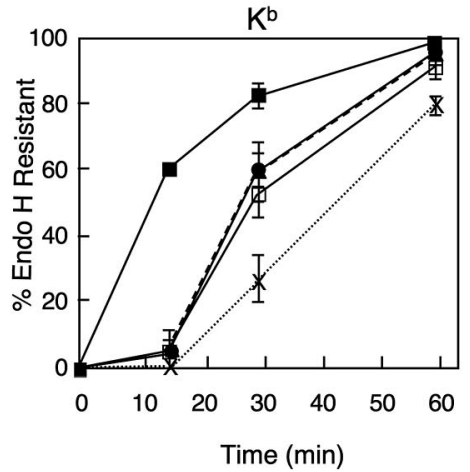

MHC class I D
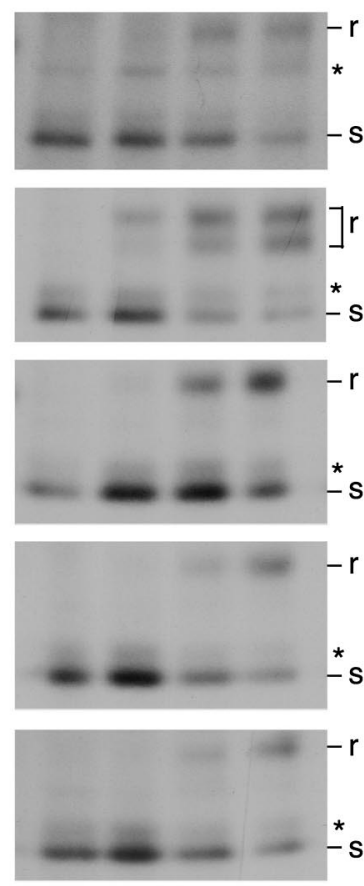

$\begin{array}{llll}0 & 30 & 60 & 90\end{array}$

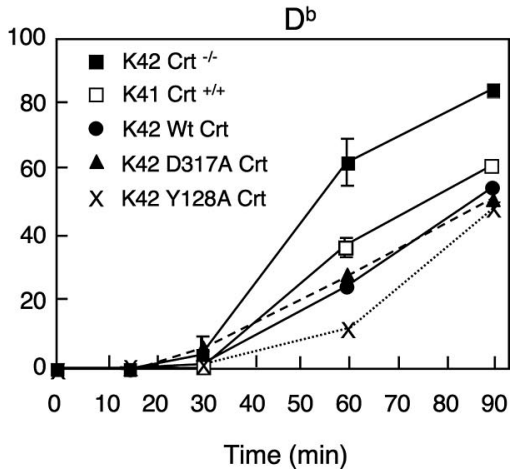

Figure 7. Both wild-type and lectin-deficient Crt retard ER-to-Golgi transport of assembling class I molecules. (A) The indicated cell lines were radiolabeled for $10 \mathrm{~min}$ with $\left.{ }^{35} \mathrm{~S}\right]$ Met and chased with unlabeled Met for various times. Cells were then lysed and $\mathrm{H}-2 \mathrm{~K}^{\mathrm{b}}$ and $\mathrm{D}^{\mathrm{b}}$ molecules were immunoisolated sequentially first with anti- 8 antiserum followed by a combination of mAbs $28-14-8 \mathrm{~S}$ and B22-249.R1. Isolated proteins were digested with endo $\mathrm{H}$ before analysis by SDS-PAGE. The mobilities of endo H-sensitive (s) and -resistant (r) heavy chains are indicated. Note that in $\mathrm{Crt}^{-/-} \mathrm{K} 42$ cells two bands are designated as endo $\mathrm{H}$ resistant for $\mathrm{D}^{\mathrm{b}}$. These appear variably between experiments; the slower band corresponds to $\mathrm{D}^{\mathrm{b}}$ molecules with all three oligosaccharides processed to complex forms whereas the faster band corresponds to molecules that possess 1 immature and 2 complex oligosaccharides. Both represent mature, Golgi-processed molecules and they are combined when calculating the percentage of endo H-resistant heavy chains. Asterisks denote nonspecific bands. (B) Fluorograms in A were scanned and endo $\mathrm{H}$-sensitive and endo $\mathrm{H}$ resistant band intensities were quantified using NIH ImageJ software (http://rsb.info.nih.gov/ij/). The endo H-resistant heavy chain was then calculated as a percentage of the total heavy chain signal at each time point. Error bars represent the SE values of three independent experiments for $\mathrm{K}^{\mathrm{b}}$ and two independent experiments for $\mathrm{D}^{\mathrm{b}}$. opeptidases and/or mediate delivery of peptides to the binding groove of class I molecules. Finally, given the more rapid export of peptide-receptive class I molecules out of the ER in cells lacking Crt, it is possible that Crt, through its C-terminal KDEL retrieval motif, contributes to quality control of class I molecules by recycling the PLC between the Golgi and ER until optimal peptides have been loaded (Hsu et al., 1991).

However Crt functions to promote peptide loading, a substantial body of evidence has accumulated suggesting that its interaction with class I H chains and with the PLC is mediated largely through its ability to bind monoglucosylated oligosaccharides. For example, treatment of cells with a glucosidase inhibitor to prevent the formation of monoglucosylated oligosaccharides results in a reduced (but not eliminated) Crt-class I interaction and a corresponding reduction of class I in the PLC (Sadasivan et al., 1996). Reduced Crt association was also observed with a class I molecule mutated to remove one of its glycans at residue 86 (Harris et al., 1998). Consistent with these findings, in vitro studies using immobilized monoglucosylated free $\mathrm{H}$ chains, empty $\mathrm{H}$ chain- $\beta_{2} \mathrm{~m}$ heterodimers and peptide loaded class I con- cluded that the glycan is necessary for Crt binding. In the absence of the lectin-oligosaccharide interaction, Crt failed to bind to any of these species, suggesting a lack of ability to discriminate between class I conformational states through polypeptide-based interactions (Wearsch et al., 2004). Additional studies have shown that class I molecules within the PLC possess $\sim 50 \%$ monoglucosylated oligosaccharides (Radcliffe et al., 2002) and that the addition of a glucosidase inhibitor after formation of the PLC results in impaired dissociation of class I from the PLC, presumably due to the inability of glucosidase II to deglucosylate $\mathrm{H}$ chain oligosaccharides (van Leeuwen and Kearse, 1996). These findings have led to models in which Crt uses lectin-oligosaccharide interactions to recruit empty $\mathrm{H}$ chain- $\beta_{2} \mathrm{~m}$ heterodimers into the PLC (Sadasivan et al., 1996; Wearsch and Cresswell, 2007) and, that once in the complex, the folding sensor UGGT monitors class I conformational state and ensures that peptide-deficient conformers remain monoglucosylated and Crt-associated. On peptide loading, UGGT no longer acts on the native conformer and deglucosylation and Crt dissociation can occur (Elliott and Williams, 2005). 
In this context, it is remarkable that our Crt mutants, demonstrably lacking lectin function both in vitro and in cells, are fully capable of substituting for wild type Crt in class I biogenesis. These mutants were incorporated into the PLC and they supported the assembly of other components into the PLC as well. This contrasts with previous studies using a glucosidase inhibitor to block the lectin component of the class I-Crt interaction wherein reduced incorporation of class I into the PLC was observed (Sadasivan et al., 1996). Furthermore, we found that in the absence of lectin function the mutants complemented the peptide loading defect observed in Crt-deficient cells just as efficiently as wild-type Crt. They also were as effective as wild-type Crt in ER quality control, restoring normal ER-to-Golgi export kinetics to assembling class I molecules.

How can these seemingly disparate results be rationalized? First, regarding the different phenotypes observed in class I biogenesis when glucosidase inhibitors are used versus lectin-deficient Crt, it is important to note that inhibitors such as castanospermine are not selective for preventing $\mathrm{Crt}$ interactions with class I oligosaccharides. Castanospermine also affects $\mathrm{Cnx}$ interactions that occur at the earliest stages of $\mathrm{H}$ chain folding and, furthermore, alters the oligosaccharide structure of all nascent Asn-linked glycoproteins (including class I $\mathrm{H}$ chains) with unknown effects on their folding. Indeed, castanospermine treatment modestly impairs early $\mathrm{H}$ chain folding of human class I (Tector and Salter, 1995) and profoundly impairs mouse class I H chain folding and assembly with $\beta_{2} \mathrm{~m}$ (Vassilakos et al., 1996), events that precede Crt binding and that are required for incorporation of class I into the PLC. Cnx is also involved in the assembly of the PLC before class I molecules are incorporated (Diedrich et al., 2001). Thus, the use of lectin-deficient Crt mutants offers a much more selective approach to assess the importance of the lectin component of the Crt-H chain interaction in class I biogenesis. Second, concerning the reported importance of monoglucosylated oligosaccharides in recruiting $\mathrm{Crt}$ (or $\mathrm{Cnx}$ ) to class I molecules, there are several contrary studies indicating that Crt or Cnx are indeed capable of associating with class I molecules through polypeptide-based interactions. For example, immunoisolated complexes of $\mathrm{Cnx}$ and mouse or human class I H chains could be completely deglycosylated by endo $\mathrm{H}$ treatment without dissociation of the complex (Ware et al., 1995; Zhang et al., 1995). In addition, treatment of cells with glucosidase inhibitors did not prevent interactions of $\mathrm{Cnx}$ with certain human or mouse class I molecules (Danilczyk and Williams, 2001). We have also shown that lectin-deficient $\mathrm{Cnx}$ is fully competent to associate with free class I H chains and prevent their premature degradation when coexpressed in Drosophila cells (Leach and Williams, 2004). For Crt, in vitro binding experiments have shown that this chaperone can interact at $37^{\circ} \mathrm{C}$ with nonglycosylated class I (Rizvi et al., 2004) as well as to a variety of nonglycosylated peptides (Sandhu et al., 2007). Coupled with demonstrations that Cnx or Crt can selectively bind nonnative and unglycosylated protein conformers and suppress their aggregation under physiological conditions (Saito et al., 1999; Brockmeier and Williams, 2006), it is apparent that lectin-oligosaccharide interactions are not the sole means whereby these chaperones can associate with protein folding intermediates.

Why have such contacts been difficult to observe in the previous studies on Crt and class I molecules described above? In the experiments testing for Crt-substrate interactions by coimmunoisolation, we have shown that polypeptide-mediated interactions are quite labile, differ in strength between different substrates, and can be missed if the im- munoisolations are not performed rapidly and under mild conditions (Danilczyk and Williams, 2001). Indeed, previous investigations on Crt-class I interactions showed that they were strongly reduced but not eliminated after treatment with glucosidase inhibitors or if $\mathrm{H}$ chain glycans were removed (Sadasivan et al., 1996; Harris et al., 1998). In the in vitro interactions between recombinant $\mathrm{Crt}$ and various assembly states of class I, it is possible that relevant polypeptide interaction sites were not accessible when the substrates were immobilized on beads or on plastic in the binding assays (Wearsch et al., 2004). Finally, the delayed dissociation of class I from the PLC after the late addition of glucosidase inhibitors does not argue against polypeptide-based interactions but rather confirms lectin-oligosaccharide interactions as one mode of association occurring in the complex (van Leeuwen and Kearse, 1996).

Despite the difficulties detecting nonlectin-based associations between Crt and class I molecules in vitro or in cells, it is clear from the present experiments with the lectin-deficient mutants that such interactions must take place within the PLC in living cells. Furthermore, these nonlectin-based associations are likely occurring in a regulated manner that is sensitive to substrate conformational state. Otherwise it is difficult to envision how the PLC containing lectin-deficient Crt could disassemble with apparently normal kinetics (measured indirectly as ER-to-Golgi transport rates of class I molecules, which closely mirror the rate of PLC disassembly; Suh et al., 1994). The previously demonstrated polypeptide-based interaction of Crt with nonnative substrate conformers is an obvious candidate for the nonlectin association that we have observed. This mode of substrate association is strongly enhanced by the mM ATP concentrations that are likely present in the ER (Saito et al., 1999; Brockmeier and Williams, 2006), suggesting that nucleotide may regulate binding and release cycles that terminate when nonnative interaction sites on the substrate become buried. However, it is also possible that the ERp57-tapasin conjugate provides an important interaction site for lectin-deficient $\mathrm{Crt}$. In vitro studies have shown that this conjugate undergoes regulated interaction with class I molecules as a function of peptide occupancy in the class I binding groove (Wearsch and Cresswell, 2007). Given that Crt associates directly with ERp57 through the tip of its extended arm domain (Frickel et al., 2002), such an interaction could provide an explanation for our observations. However, the Crt-ERp57 interaction is quite weak (Frickel et al., 2002), an order of magnitude weaker than lectin-oligosaccharide binding (Kapoor et al. 2004), and it is likely that a combination of the Crt-ERp57 association and polypeptide-based contacts between Crt and the class I H chain confer the observed robust inclusion of lectin-deficient Crt into the PLC (Figure 6). Future studies in which ERp57 binding-deficient Crt is expressed in $\mathrm{Crt}^{-/-}$ K42 cells should help to resolve the relative contributions of the two modes of interaction within the PLC.

It will also be of considerable interest to examine the extent to which lectin-deficient Crt (or Cnx) can promote the in vivo folding of proteins other than class I molecules. The pulse-chase experiments in Figure 2 indicate that lectinindependent interactions between Crt and its substrates are commonplace. Furthermore, the similarities in rates of dissociation of diverse substrates from wild-type versus lectindeficient Crt suggest that polypeptide-based interactions may be sensitive to changes in substrate conformational state as has been established for the wild-type chaperone (for review, see Bergeron et al., 1994). This is consistent with in vitro experiments demonstrating that Crt and Cnx can interact with and suppress the aggregation of nonnative 
conformers of unglycosylated proteins but do not associate with the native species (Ihara et al., 1999; Saito et al., 1999). Perhaps the folding of different glycoproteins will exhibit a range of dependencies on the lectin functions of $\mathrm{Cnx}$ and $\mathrm{Crt}$ because our previous studies have suggested that various glycoprotein substrates differ significantly in the stabilities of their association with these chaperones when lectin-oligosaccharide binding is prevented (Danilczyk and Williams, 2001).

\section{ACKNOWLEDGMENTS}

We gratefully acknowledge Brian Barber, Ron Germain, Jennifer Gommerman, Marek Michalak, Jacques Neefjes, and Young Yang and for gifts of cells and reagents and to Emmanuelle Cordat for help with the Moloney virus expression system. This work was supported by grants from the Canadian Cancer Society and the Canadian Institutes for Health Research (to D.B.W.) and from Cancer Research UK (to T.E.). U.B. is a postdoctoral trainee of the Canadian Institutes of Health Research Strategic Training Program in the Structural Biology of Membrane Proteins Linked to Disease.

\section{REFERENCES}

Bergeron, J. J., Brenner, M. B., Thomas, D. Y., and Williams, D. B. (1994) Calnexin: a membrane-bound chaperone of the endoplasmic reticulum. Trends Biochem. Sci. 19, 124-128.

Brockmeier, A., and Williams, D. B. (2006). Potent lectin-independent chaperone function of calnexin under conditions prevalent within the lumen of the endoplasmic reticulum. Biochemistry 45, 12906-12916.

Caramelo, J. J., Castro, O. A., Alonso, L. G., De Prat-Gay, G., and Parodi, A. J. (2003). UDP-Glc:glycoprotein glucosyltransferase recognizes structured and solvent accessible hydrophobic patches in molten globule-like folding intermediates. Proc. Natl. Acad. Sci. USA 100, 86-91.

Cresswell, P., Ackerman, A. L., Giodini, A., Peaper, D. R., and Wearsch, P. A (2005). Mechanisms of MHC class I-restricted antigen processing and crosspresentation. Immunol. Rev. 207, 145-157.

Danilczyk, U. G., and Williams, D. B. (2001). The lectin chaperone calnexin utilizes polypeptide-based interactions to associate with many of its substrates in vivo. J. Biol. Chem. 276, 25532-25540.

David, V., Hochstenbach, F., Rajagopalan, S., and Brenner, M. B. (1993). Interaction with newly synthesized and retained proteins in the endoplasmic reticulum suggests a chaperone function for human integral membrane protein IP90 (calnexin). J. Biol. Chem. 268, 9585-9592.

Degen, E., Cohen-Doyle, M. F., and Williams, D. B. (1992). Efficient dissociation of the p88 chaperone from major histocompatibility complex class I molecules requires both beta 2-microglobulin and peptide. J. Exp. Med. 175, 1653-1661.

Diedrich, G., Bangia, N., Pan, M., and Cresswell, P. (2001). A role for calnexin in the assembly of the MHC class I loading complex in the endoplasmic reticulum. J. Immunol. 166, 1703-1709.

Elliott, T., and Williams, A. (2005). The optimization of peptide cargo bound to MHC class I molecules by the peptide-loading complex. Immunol. Rev. 207, 89-99.

Frickel, E. M., Riek, R., Jelesarov, I., Helenius, A., Wuthrich, K., and Ellgaard, L. (2002). TROSY-NMR reveals interaction between ERp57 and the tip of the calreticulin P-domain. Proc. Natl. Acad. Sci. USA 99, 1954-1959.

Gao, B., Adhikari, R., Howarth, M., Nakamura, K., Gold, M. C., Hill, A. B. Knee, R., Michalak, M., and Elliott, T. (2002). Assembly and antigen-presenting function of MHC class I molecules in cells lacking the ER chaperone calreticulin. Immunity 16, 99-109.

Gopalakrishnapai, J., Gupta, G., Karthikeyan, T., Sinha, S., Kandiah, E., Gemma, E., Oscarson, S., and Surolia, A. (2006). Isothermal titration calorimetric study defines the substrate binding residues of calreticulin. Biochem. Biophys. Res. Commun. 351, 14-20.

Harris, M. R., Yu, Y. Y., Kindle, C. S., Hansen, T. H., and Solheim, J. C. (1998) Calreticulin and calnexin interact with different protein and glycan determinants during the assembly of MHC class I. J. Immunol. 160, 5404-5409.

Hebert, D. N., Foellmer, B., and Helenius, A. (1995). Glucose trimming and reglucosylation determine glycoprotein association with calnexin in the endoplasmic reticulum. Cell 81, 425-433.

Helenius, A., and Aebi, M. (2004). Roles of N-linked glycans in the endoplasmic reticulum. Annu. Rev. Biochem. 73, 1019-1049.
Hsu, V. W., Yuan, L. C., Nuchtern, J. G., Lippincott-Schwartz, J., Hammerling, G. J., and Klausner, R. D. (1991). A recycling pathway between the endoplasmic reticulum and the Golgi apparatus for retention of unassembled MHC class I molecules. Nature 352, 441-444

Ihara, Y., Cohen-Doyle, M. F., Saito, Y., and Williams, D. B. (1999). Calnexin discriminates between protein conformational states and functions as a molecular chaperone in vitro. Mol. Cell 4, 331-341.

Jones, B., and Janeway, C. A., Jr. (1981). Cooperative interaction of B lymphocytes with antigen-specific helper T lymphocytes is MHC restricted. Nature 292, 547-549.

Kapoor, M., Ellgaard, L., Gopalakrishnapai, J., Schirra, C., Gemma, E., Oscarson, S., Helenius, A., and Surolia, A. (2004). Mutational analysis provides molecular insight into the carbohydrate-binding region of calreticulin: pivotal roles of tyrosine-109 and aspartate-135 in carbohydrate recognition. Biochemistry 43 , 97-106.

Leach, M. R., Cohen-Doyle, M. F., Thomas, D. Y., and Williams, D. B. (2002) Localization of the lectin, ERp57 binding, and polypeptide binding sites of calnexin and calreticulin. J. Biol. Chem. 277, 29686-29697.

Leach, M. R., and Williams, D. B. (2004). Lectin-deficient calnexin is capable of binding class I histocompatibility molecules in vivo and preventing their degradation. J. Biol. Chem. 279, 9072-9079.

Lemke, H., Hammerling, G. J., and Hammerling, U. (1979). Fine specificity analysis with monoclonal antibodies of antigens controlled by the major histocompatibility complex and by the Qa/TL region in mice. Immunol. Rev. $47,175-206$

Meunier, L., Usherwood, Y. K., Chung, K. T., and Hendershot, L. M. (2002). A subset of chaperones and folding enzymes form multiprotein complexes in endoplasmic reticulum to bind nascent proteins. Mol. Biol. Cell 13, 44564469 .

Nakamura, K. et al. (2001). Functional specialization of calreticulin domains. J. Cell Biol. 154, 961-972.

Neijssen, J., Herberts, C., Drijfhout, J. W., Reits, E., Janssen, L., and Neefjes, J. (2005). Cross-presentation by intercellular peptide transfer through gap junctions. Nature $434,83-88$.

Ozato, K., Hansen, T. H., and Sachs, D. H. (1980). Monoclonal antibodies to mouse MHC antigens. II. Antibodies to the H-2Ld antigen, the products of a third polymorphic locus of the mouse major histocompatibility complex. J. Immunol. 125, 2473-2477.

Parodi, A. J. (2000). Role of N-oligosaccharide endoplasmic reticulum processing reactions in glycoprotein folding and degradation. Biochem. J. 348, $1-13$.

Peterson, J. R., Ora, A., Van, P. N., and Helenius, A. (1995). Transient, lectin-like association of calreticulin with folding intermediates of cellular and viral glycoproteins. Mol. Biol. Cell 6, 1173-1184.

Porgador, A., Yewdell, J. W., Deng, Y., Bennink, J. R., and Germain, R. N (1997). Localization, quantitation, and in situ detection of specific peptideMHC class I complexes using a monoclonal antibody. Immunity 6, 715-726.

Radcliffe, C. M., Diedrich, G., Harvey, D. J., Dwek, R. A., Cresswell, P., and Rudd, P. M. (2002). Identification of specific glycoforms of major histocompatibility complex class I heavy chains suggests that class I peptide loading is an adaptation of the quality control pathway involving calreticulin and ERp57. J. Biol. Chem. 277, 46415-46423.

Rizvi, S. M., Mancino, L., Thammavongsa, V., Cantley, R. L., and Raghavan M. (2004). A polypeptide binding conformation of calreticulin is induced by heat shock, calcium depletion, or by deletion of the C-terminal acidic region. Mol. Cell 15, 913-923.

Rodan, A. R., Simons, J. F., Trombetta, E. S., and Helenius, A. (1996). N-linked oligosaccharides are necessary and sufficient for association of glycosylated forms of bovine RNase with calnexin and calreticulin. EMBO J. 15, 6921-6930.

Sadasivan, B., Lehner, P. J., Ortmann, B., Spies, T., and Cresswell, P. (1996) Roles for calreticulin and a novel glycoprotein, tapasin, in the interaction of MHC class I molecules with TAP. Immunity 5, 103-114.

Saito, Y., Thara, Y., Leach, M. R., Cohen-Doyle, M. F., and Williams, D. B. (1999). Calreticulin functions in vitro as a molecular chaperone for both glycosylated and non-glycosylated proteins. EMBO J. 18, 6718-6729.

Sandhu, N., Duus, K., Jorgensen, C. S., Hansen, P. R., Bruun, S. W., Pedersen L. O., Hojrup, P., and Houen, G. (2007). Peptide binding specificity of the chaperone calreticulin. Biochim. Biophys. Acta 1774, 701-713.

Smith, M. H., Parker, J. M., Hodges, R. S., and Barber, B. H. (1986). The preparation and characterization of anti-peptide heteroantisera recognizing subregions of the intracytoplasmic domain of class I H-2 antigens. Mol. Immunol. 23, 1077-1092. 
Spee, P., and Neefjes, J. (1997). TAP-translocated peptides specifically bind proteins in the endoplasmic reticulum, including gp96, protein disulfide isomerase and calreticulin. Eur. J. Immunol. 27, 2441-2449.

Spiro, R. G., Zhu, Q., Bhoyroo, V., and Soling, H. D. (1996). Definition of the lectin-like properties of the molecular chaperone, calreticulin, and demonstration of its copurification with endomannosidase from rat liver Golgi. J. Biol. Chem. 271, 11588-11594.

Stronge, V. S., Saito, Y., Ihara, Y., and Williams, D. B. (2001). Relationship between calnexin and $\mathrm{BiP}$ in suppressing aggregation and promoting refolding of protein and glycoprotein substrates. J. Biol. Chem. 276, 39779-39787.

Suh, W. K., Cohen-Doyle, M. F., Fruh, K., Wang, K., Peterson, P. A., and Williams, D. B. (1994). Interaction of MHC class I molecules with the transporter associated with antigen processing. Science 264, 1322-1326.

Suh, W. K., Derby, M. A., Cohen-Doyle, M. F., Schoenhals, G. J., Fruh, K., Berzofsky, J. A., and Williams, D. B. (1999). Interaction of murine MHC class I molecules with tapasin and TAP enhances peptide loading and involves the heavy chain alpha3 domain. J. Immunol. 162, 1530-1540.

Tatu, U., and Helenius, A. (1997). Interactions between newly synthesized glycoproteins, calnexin and a network of resident chaperones in the endoplasmic reticulum. J. Cell Biol. 136, 555-565.

Tector, M., and Salter, R. D. (1995). Calnexin influences folding of human class I histocompatibility proteins but not their assembly with beta 2-microglobulin. J. Biol. Chem. 270, 19638-19642.

Thammavongsa, V., Mancino, L., and Raghavan, M. (2005). Polypeptide substrate recognition by calnexin requires specific conformations of the calnexin protein. J. Biol. Chem. 280, 33497-33505.

Thomson, S. P., and Williams, D. B. (2005). Delineation of the lectin site of the molecular chaperone calreticulin. Cell Stress Chaperones 10, 242-251.
Townsend, A., Ohlen, C., Bastin, J., Ljunggren, H. G., Foster, L., and Karre, K. (1989). Association of class I major histocompatibility heavy and light chains induced by viral peptides. Nature 340, 443-448.

van Leeuwen, J. E., and Kearse, K. P. (1996). Deglucosylation of N-linked glycans is an important step in the dissociation of calreticulin-class I-TAP complexes. Proc. Natl. Acad. Sci. USA 93, 13997-14001.

Vassilakos, A., Cohen-Doyle, M. F., Peterson, P. A., Jackson, M. R., and Williams, D. B. (1996). The molecular chaperone calnexin facilitates folding and assembly of class I histocompatibility molecules. EMBO J. 15, 1495-1506.

Ware, F. E., Vassilakos, A., Peterson, P. A., Jackson, M. R., Lehrman, M. A., and Williams, D. B. (1995). The molecular chaperone calnexin binds Glc1Man9GlcNAc2 oligosaccharide as an initial step in recognizing unfolded glycoproteins. J. Biol. Chem. 270, 4697-4704.

Wearsch, P. A., and Cresswell, P. (2007). Selective loading of high-affinity peptides onto major histocompatibility complex class I molecules by the tapasin-ERp57 heterodimer. Nat. Immunol. 8, 873-881.

Wearsch, P. A., Jakob, C. A., Vallin, A., Dwek, R. A., Rudd, P. M., and Cresswell, P. (2004). Major histocompatibility complex class I molecules expressed with monoglucosylated N-linked glycans bind calreticulin independently of their assembly status. J. Biol. Chem. 279, 25112-25121.

Williams, D. B. (2006). Beyond lectins: the calnexin/calreticulin chaperone system of the endoplasmic reticulum. J. Cell Sci. 119, 615-623.

Zapun, A., Petrescu, S. M., Rudd, P. M., Dwek, R. A., Thomas, D. Y., and Bergeron, J. J. (1997). Conformation-independent binding of monoglucosylated ribonuclease B to calnexin. Cell 88, 29-38.

Zhang, Q., Tector, M., and Salter, R. D. (1995). Calnexin recognizes carbohydrate and protein determinants of class I major histocompatibility complex molecules. J. Biol. Chem. 270, 3944-3948. 